Revista Brasileira de História \& Ciências Sociais - RBHCS Vol. $12 \mathrm{~N}^{\circ} 23$, Janeiro - Junho de 2020

\title{
Percepções sobre as consequências e prejuízos de inundações: estudo aplicado em Pinhais, Paraná.
}

\section{Perception on the consequences and flood losses: a study applied in Pinhais, Paraná.}

\author{
Murilo Noli da Fonseca* \\ Larissa Maria da Silva Ferentz**
}

Resumo: As preocupações pelos impactos negativos enfrentados nas comunidades urbanas, decorrente de desastres, tem ganhado força à medida que organismos internacionais e nacionais recomendam a realização de estudos que buscam compreender como os riscos e as medidas que visem a sua redução, são percebidos. O objetivo do artigo é avaliar a percepção de indivíduos perante as consequências e prejuízos de inundações. Foi realizado um estudo de caso no Conjunto Habitacional "Moradias Bonilauri” em Pinhais, no Paraná, com aplicação de oito entrevistas. Os principais prejuízos identificados se relacionam às perdas de bens materiais, pressões psicológicas e o sentimento de abandono por parte do poder público. No entanto, mesmo com todos os problemas elencados, os moradores se sentem pertencentes ao lugar. Conclui-se que a percepção é um importante instrumento na compreensão da relação humanoambiente, principalmente para estudos sobre vulnerabilidades socioambientais e gestão dos riscos às inundações.

Palavras-Chave: Percepção de Risco. Desastres. Resiliência.

Abstract: Concerns about the negative impacts, resulting from disasters, faced in urban communities, have gained strength as international and national organizations have recommended carrying out studies to understand how the risks and measures aimed at reducing them are perceived. The objective of the article is to assess the perception of individuals in face of the consequences and losses of floods. A case study was carried out at the Housing Complex "Moradias Bonilauri” in Pinhais, Paraná, with the application of eight interviews. The main

\footnotetext{
* Mestrando em Gestão Urbana pela Pontifícia Universidade Católica do Paraná. Especialista em Gestão Ambiental de Empresas pelo Instituto Souza. Bacharel em Geografia pela Universidade Federal do Paraná.

** Doutoranda e Mestra em Gestão Urbana pela Pontifícia Universidade Católica do Paraná. Especialista em Gestão Ambiental pela Faculdade Souza. Engenheira Ambiental pela PUCPR.
} 
Revista Brasileira de História \& Ciências Sociais - RBHCS

losses identified are related to the loss of material goods, psychological pressures and the feeling of abandonment by the government. However, even with all the problems listed, residents feel they belong to the place. We conclude that perception is an important tool in understanding the human-environment relationship, especially for studies on socio-environmental vulnerabilities and flood risk management.

Keywords: Risk Perception. Disasters. Resilience.

\section{INTRODUÇÃO}

As interações entre os seres humanos e o ambiente que o circunda sempre preocuparam os diversos pesquisadores. O interesse por essa relação é encontrado já na Antiguidade, na civilização grega, com Heródoto, e no século XVIII, na França, com Montesquieu, quando se procurou reconhecer as escritas dos povos em função das condições climáticas e morfológicas (ANDRADE, 1987). Não obstante, é a partir do período pós-Segunda Guerra Mundial que estudos sobre percepção ganham destaque, especialmente com base na corrente humanista, que abdica a demasia cientificista, apreciações positivistas, reducionistas e mecanicistas, e onde o homem é considerado exclusivamente como uma variável nas análises (ZANELLA, 2006).

A corrente humanista evoca uma nova abordagem na relação ser humanoambiente, no qual o processo de conhecimento não afasta os fatos dos valores, o sentimento da razão e o saber da apreensão. Em outras palavras, "toda a ação humana está atrelada a um contexto, seja ele social, físico ou econômico, porém, a abordagem deve ser integral, jamais perdendo de vista o todo, embora o estudo possa estar centrado apenas na parte" (TEIXEIRA, 2001, p.28). Na Geografia, tal corrente ensejou transformações no pensamento então influenciado pelo determinismo e pelo possibilismo, de modo que há o surgimento de uma linha nomeada Geopsicologia. Nela, seus expoentes buscam entender como os povos primitivos dominados se relacionavam com a natureza e como percebiam e organizavam o espaço (ANDRADE, 1987).

Atrelado a isso, Claval (2010) percorre pela geografia grega até chegar aos tempos modernos, com destaque à geografia humana. Para o autor, é importante que essa área seja compreendida como as experiências e práticas do homem com 
Revista Brasileira de História \& Ciências Sociais - RBHCS

o espaço em que vive. A geografia está presente nas práticas, nas habilidades, nos conhecimentos que todos sempre mobilizamos em nossa vida diária, nos preceitos que os governos observam para dirigir seus países ou nos procedimentos aos quais recorrem os empreendedores (CLAVAL, 2010, p.8).

Atualmente, a percepção do espaço se faz cada vez mais necessária pois o crescimento populacional descomedido e desordenado, principalmente em países em vias de desenvolvimento, atrelado a políticas ineficazes de uso de solo, gera cada vez mais desastres no meio urbano. Os desastres resultam da ação de eventos perigosos que ocorrem em determinada área geográfica, nomeadamente com condições sociais vulneráveis (como resultado de consequências cumulativas de decisões - sejam elas individuais e/ou coletivas - previamente adotadas, ligadas à organização e ao planejamento do território), durante um período de tempo curto, culminando na destruição da morfologia de uma comunidade e sobrepujando a resiliência de tal (WORLD BANK INSTITUTIONS, 2010). Como resultado, tem-se os prejuízos materiais, econômicos, sociais e psicológicos das pessoas afetadas.

Tendo em vista isso, o presente artigo tem como objetivo analisar a percepção das consequências e prejuízos resultantes das inundações, por meio de um estudo de caso realizado no Conjunto Habitacional "Moradias Bonilauri” no município de Pinhais, no estado do Paraná.

\section{A IMPORTÂNCIA DA PERCEPÇÃO SOBRE O AMBIENTE}

Os primeiros estudos com base na percepção foram desenvolvidos pelos anglo-saxões e eram voltados para o aspecto econômico, onde se via a necessidade de estudar o comportamento humano e criar modelos que visassem alcançar um nível de satisfação. Há também os trabalhos de Julian Wolper na década de 1960, que buscou entender o grau de satisfação de fazendeiros e, depois, os movimentos migratórios, e de Anne White, que estudou o comportamento e a percepção de indivíduos atingidos por inundações nos EUA (CLAVAL, 2001).

Ressalta-se que a abordagem perceptiva não é pautada pela “distribuição espacial dos fatos sociais, mas a maneira como as pessoas vivem nos lugares onde residem ou os que visitam, deles extraindo uma experiência” (CLAVAL, 2001, 
p.46). Os indivíduos percebem conforme a sua perspectiva individual, refletindo a natureza, as experiências e as aspirações daquele que percebe. Ou seja, pode-se garantir que não há uma percepção predominante. Sem ela, as pessoas permaneceriam interligadas ao ambiente exclusivamente pela forma física (SARTORI, 2014). Com base nisso, há surgimento do termo “Topofilia", inicialmente mencionado por Bachelard (1969), mas que ganha ênfase e repercussão com Tuan (2012). Este autor ampliou o conceito ao incorporar experiências agradáveis das paisagens e dos lugares (ZANELLA, 2006). A Topofilia se refere ao elo afetivo entre o ser humano e o lugar ou ambiente físico. Em oposição a este termo, Tuan (2012) criou o termo Topofobia, que introduz a ideia de paisagem do medo.

Os estudos com uma abordagem perceptiva ajudam a entender a interação ininterrupta entre o ser humano e o ambiente, envolvendo o que é experienciado (ambiente) e o que está experienciando (indivíduo). É com base na vivência diferenciada dos fenômenos que o ser humano desenvolve sua realidade social. Isto é, representa o modo como os indivíduos organizam mentalmente o ambiente que o rodeia no âmbito individual (memórias, história de vida, relações com o lugar, situação e posição) e de mediação cultural e social em que está inserido (religião, grupo étnico, família, situação econômica). Isto é, a variabilidade humana suscita uma vasta gama de experiências de tal modo que os estudos sobre percepção necessitam pôr em evidência a influência mútua entre ambiente e ser humano (MACHADO, 1983).

Esse processo de interação ocorre através dos sentidos, que induzem às sensações e, desse modo, à percepção. Cabe realçar a necessidade de distinguir os termos sensação e percepção. O primeiro é fruto do reenvio ao cérebro da estimulação dos órgãos dos sentidos por rotas neurais específicas e servem como base para o desenvolvimento da experiência em um ato sucessivo. Já a segunda deriva da primeira como interpretação do cérebro aos estímulos recebidos. Oliveira (2000) diferencia a percepção da inteligência. A presença de um elemento é o que fornece o conhecimento por conotação e sua percepção está ligada a um corpo sensorial, e a inteligência permite usar a função simbólica para evocar os objetos quando ausentes. 
Revista Brasileira de História \& Ciências Sociais - RBHCS Vol. $12 \mathrm{~N}^{\circ} 23$, Janeiro - Junho de 2020

De uma forma geral, a percepção é composta por dois sistemas: o sensorial (auditivo, visual, olfativo e tátil-cinestésico) e o não sensorial (imagem mental, cultura, memória, experiência, transmissão da informação, orientação geográfica e leitura) (OLIVEIRA; MACHADO, 2004). Da mesma forma que a sensação e percepção, é imprescindível diferenciar o ver e o perceber. O primeiro emana de uma sensação reproduzida através da observação de um elemento e o perceber compreende o conhecimento através dos sentidos e da coordenação interna do que foi apreendido do mundo externo.

Apreende-se que as sensações constituem a primeira etapa da experiência humana no ambiente. O outro passo corresponde à percepção, de cuja interpretação cerebral os sentidos falam (SARTORI, 2014). No entanto, é fundamental sublinhar que a mente opera como um elemento selecionador, ou seja, a habilidade de focar certas sensações está fundamentada em uma relação entre a sensação que chega e a sensação que é esperada, com base nas percepções antecedentes (BERENT, 1981). Deste modo, a percepção pode ser compreendida como um processo mental seletivo através do qual os seres humanos se relacionam com o mundo a partir das sensações conduzidas ao cérebro pelos sentidos (SARTORI, 2014).

O processo de percepção também ocorre através de estruturas perceptivas e cognitivas (OLIVEIRA 2000). As perceptivas consistem em estímulos externos, que são apreendidos através dos cinco sentidos e onde a visão é a que se sobressai e dela depende para constituir o espaço (TUAN, 2012). As cognitivas são as que englobam a inteligência devido à mente não operar apenas "a partir dos sentidos e nem recebe essas sensações passivamente; existem contribuições ativas do sujeito ao processo perceptivo desde a motivação a decisão e conduta” (DEL RIO, 1996, p.3).

Os sentidos podem ser considerados como instrumentos por meio do qual os seres humanos entram em contato com o meio físico. Eles permitem compreender o ambiente externo e adquirem, simultaneamente, os estímulos do meio e do indivíduo (SARTORI, 2014). No entanto, as pessoas, no seu dia-a-dia, empregam somente uma parte dessa potencialidade para experienciar o ambiente em que está sujeito e sua cultura. Os esquimós Aivilik, por exemplo, têm no olfato, audição e tato seus principais sentidos de direção, conduzindo-se 
Revista Brasileira de História \& Ciências Sociais - RBHCS

pela orientação e cheiro dos ventos e pela sensação da neve e do gelo ao pisar (TUAN, 1983).

Com base nisso, apreende-se que a própria realidade não é observada da mesma maneira por duas pessoas e dois grupos sociais não fazem o mesmo julgamento do meio, já que distintos fatores como a cultura, o sexo, a idade e as experiências com o lugar influenciam no processo perceptivo. As diferenças fisiológicas entre homens e mulheres e suas inserções na vida social e o posicionamento sobre elementos ambientais também afetam a relação destes atores com o ambiente (TUAN, 2012). "As pessoas têm uma reação emotiva diante dos lugares em que vivem, que percorrem regularmente ou que visitam eventualmente" (CLAVAL, 2010, p.39).

\section{EVENTOS EXTREMOS, RISCOS E DESASTRES}

Desde os primórdios da humanidade, o ser humano possui uma preocupação com os fenômenos que são originados na atmosfera. Essa preocupação é influenciada pela interdependência das condições climáticas e, sobretudo, pelas repercussões geradas por tais fenômenos sobre as atividades humanas. Dentre os eventos climáticos, os eventos extremos têm recebido cada vez mais atenção dos gestores públicos, dos pesquisadores e da sociedade devido aos desarranjos gerados no interior do espaço geográfico, pelos danos à sociedade ou pelas previsões de modelos climáticos que apontam um acréscimo de sua frequência numa conjuntura de "mudanças climáticas".

Os eventos extremos ocorrem com maior frequência e intensidade em ambientes urbanos, uma vez que nessas áreas acontece uma das maiores transformações do espaço natural, e tendem a extrapolar a capacidade de absorção de suas implicações pela sociedade, que se encontra planejada e organizada com base nos estados médios dos sistemas atmosféricos, ignorando seu ritmo e a sua variabilidade natural (MONTEIRO, 2013).

Nesse contexto, inúmeros autores inserem o conceito de hazard e o definem como sendo eventos que interrompem um ciclo ou um ritmo de ocorrência de repercussões geográficas de natureza climática e meteorológica. Ressalta-se que nem todos os eventos devem ser considerados como hazards, mas somente aqueles "que estão em relação ou ocorrendo em áreas ocupadas pelo 
Revista Brasileira de História \& Ciências Sociais - RBHCS

Acadêmicos \& Pesquisas

Vol. $12 \mathrm{~N}^{\circ} 23$, Janeiro - Junho de 2020

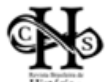

homem, gerando danos, perdas e colocando em perigo estas populações" (MARANDOLA JR.; HOGAN, 2004, p. 98). Ou seja, os eventos e processos naturais que não interagem com a sociedade não são perigosos, são apenas eventos naturais, eventos que causam a ruptura de um ritmo e ocorrem em uma determinada área.

Os impactos negativos de um evento extremo sobre a sociedade assinalam um desastre. O Emergency Events Database (EM-DATA) classifica os desastres em três categoria as: naturais, tecnológicos e complexos, conforme os seguintes critérios: 10 ou mais óbitos; 100 ou mais pessoas afetadas; declaração de estado de emergência; ou pedido de auxílio internacional. Os desastres deflagrados por eventos naturais podem ser geofísicos (terremoto, atividade vulcânica ou movimento de massa), hidrológicos (inundações, deslizamento de terra e ressacas das marés), meteorológicos (furacão, temperaturas extremas e incêndios), climatológico (seca, explosão de lago glacial e incêndios), biológico (acidente animal, epidemia e infestação de insetos), e extraterrestre (impacto e clima espacial).

No âmbito internacional, estima-se que $75 \%$ da população mundial reside em áreas que já foram atingidas por desastres. Estas áreas concentram-se em países em vias de desenvolvimento, especialmente na Ásia e na América, o que ratifica a influência das condições socioeconômicas na geração de desastres, como a expansão caótica da urbanização e a alta concentração populacional em áreas de risco. Tais desastres derivam de fenômenos e processos atmosféricos, sobretudo os hidrometeorológicos, que são responsáveis por cerca de 90\% das perdas, 72,5\% das vítimas e 75\% dos prejuízos econômicos (GUHA-SAPIR et al. 2012).

Em 2019, por exemplo, as inundações representaram 49\% das ocorrências registradas no mundo, com 33\% de pessoas afetadas e chegando a $43 \% \mathrm{em}$ número de óbitos (EM-DATA, 2020). Embora sejam fenômenos naturais desencadeados por características climáticas regionais, os eventos pluviométricos extremos de ordem negativa (inundações, alagamentos, enxurradas) são os mais expressivos nas cidades (LEOPOLD et al. 1964). Como forma de minimizar os impactos, os municípios precisam reconhecer os motivos e as implicações de um desastre, para então desenvolver estratégias, políticas que 
Revista Brasileira de História \& Ciências Sociais - RBHCS Vol. $12 \mathrm{~N}^{\circ} 23$, Janeiro - Junho de 2020

possibilitem a minimização dos riscos e das vulnerabilidades. Tais ações devem ser concretizadas antes, durante e depois de um evento adverso por meio de medidas estruturais e não estruturais (KOBIYAMA et al. 2004).

Logo, a identificação dos elementos deflagradores de desastres, ou seja, das razões que dão início aos impactos resultantes dos eventos, é essencial na percepção dos riscos, até mesmo como forma de subsidiar o desenvolvimento de políticas que visem a sua redução. Comumente, a responsabilidade pelos eventos extremos e pela situação de risco é arrogada a elementos naturais, abstratos. Os aspectos intrínsecos aos seres humanos são postos à margem da discussão, e a busca por soluções reside em análises técnicas (KATES, 1978; WHYTE, 1985).

Com isso, alguns indivíduos, seguramente, procuram excluir-se de qualquer dever no que tange às condições ambientais do lugar em que reside, sendo que os bens coletivos são rotineiramente tratados como algo sem dono (SOUZA; ZANELLA, 2010). Na aceitação dos riscos, podem-se identificar dois tipos de atitudes: as voluntárias e as involuntárias. A primeira deriva de uma escolha individual e se encontra atrelada aos benefícios oferecidos pelo local de moradia. Já a segunda resulta de uma imposição governamental, como o reassentamento, onde o risco não é aceito de modo tão passivo.

Logo, a diminuição do risco pelos indivíduos demanda um momento de sensibilidade e pretensão por alterações. Isto ocorre quando se alcança um determinado limiar que varia substancialmente em cada caso e depende de inúmeros fatores, como a gravidade do risco, o grau de exposição, o valor dos bens materiais passíveis de estragos e as características intrínsecas a cada indivíduo, entre outros (SOUZA; ZANELLA, 2010). É imprescindível lembrar que não existem "sujeitos sem” e "sujeitos com” percepção de riscos, mas que estas variam de acordo com a experiência de cada indivíduo no espaço. Conforme Souza e Zanella (2010), podem ser identificados quatro padrões de conduta individuais em face ao risco:

1. O risco não é percebido: os indivíduos não têm consciência da ameaça, pois confiam que a sua manifestação ou seus efeitos são improváveis. Comumente, tal conduta ocorre quando ainda não houve fortes impactos ou, se existiram, foram ínfimos e absorvidos facilmente. $\mathrm{O}$ risco não resulta em uma aflição e a comunidade se mantém a mercê da ocasião.

2. O risco é percebido, mas é aceito de forma passiva: as ameaças são reconhecidas e consentidas, pois são avaliadas como uma condição 
pela moradia. Por conseguinte, as pessoas têm consciência do risco devido a experiências com as situações perigosas, mas aceitam passivamente seus efeitos, posto que não encontram solução para o problema.

3. O risco é minimizado diante medidas de redução: elas são dispostas mirando a minimização dos impactos, isto é, reduzir a vulnerabilidade face ao fenômeno. No âmbito da comunidade, os sujeitos tomam consciência do risco e adotam medidas de resposta para a prevenção e controle.

4. O risco provoca a alteração/transformação no uso do solo: o limite da intolerância foi atingido e o risco determina a transformação do uso do solo, a modificação do local de residência ou a combinação de ambos.

As medidas ainda podem ser organizadas, possuir propósitos específicos (operar sobre a ameaça ou a vulnerabilidade) e ocorrer de três formas: antes do evento como prevenção, no prenúncio do acontecimento e dar-se após a sua manifestação (KATES, 1978). Isso ocorre, pois grande parcela das estratégias auxiliam os moradores apenas a tolerar as consequências dos eventos, aceitando os prejuízos resultantes. Medidas mais eficazes, como as que permitem a diminuição da vulnerabilidade ou o reassentamento e, em um horizonte mais vasto, a construção de uma cultura de risco, são pouco observadas (SOUZA; ZANELLA, 2010).

Entretanto, em algumas situações, determinadas medidas extrapolam a esfera individual e só podem ser executadas pelo poder público. Elas ocorrem sobretudo em áreas socialmente frágeis e não há garantia de sua implementação, já que o poder público se comprova impossibilitado de resolver ou minimizar o problema (SOUZA; ZANELLA, 2010). Tal circunstância auxilia ainda mais a adoção de medidas de resposta pelos indivíduos que podem ser insuficientes (WHYTE, 1985).

Sendo assim, compreender os fatores que influenciam na percepção ao risco têm sido fundamental para identificar as vulnerabilidade e o modo de adaptação das comunidades perante as situações de perigo ou de desastres ligados aos eventos climáticos extremos (CUTTER et al, 2003; DI GIULIO et al., 2012; 2013; ADGER et al., 2013). 
Revista Brasileira de História \& Ciências Sociais - RBHCS

\section{METODOLOGIA}

A presente pesquisa foi estabelecida segundo o método fenomenológico, onde se procura as essências por meio da existência. Tal método pode ser definido como sendo "um modo filosófico de reflexão a respeito da experiência consciente e uma tentativa para explicar isso em termos de significado e significância” (BUTTIMER, 1982, p.169). Ou seja, "tudo aquilo que sei do mundo, mesmo por ciência, eu o sei a partir de uma visão minha ou de uma experiência do mundo sem a qual os símbolos da ciência não poderiam dizer nada” (MERLEAU-PONTY, 1994, p. 3). Assim, uma abordagem fenomenológica e perceptiva permite explorar os valores da sociedade por meio de suas experiências com o ambiente.

Na Geografia, a Fenomenologia apresenta uma expansão durante a década de 1970. Ela é introduzida como base epistemológica para estudos do espaço vivido ou mundo vivido por meio da Geografia Humanista. Entende-se o mundo vivido como "o mundo experienciado como cenário, tanto o natural como o construído pelo homem, e como ambiente que provê sustento e uma moldura para a existência" (DARDEL, 1952, p.57). Neste período, as discussões acerca das categorias e métodos utilizados na Geografia propiciaram o desenvolvimento de estudos sobre a percepção e o meio ambiente. Tais pesquisas permitem compreender a realidade por meio de estudos das relações pessoais "com o meio ambiente, seu comportamento geográfico, de seus sentimentos e de suas ideias em relação aos espaços e aos lugares” (TUAN, 1982, p.143). Ou seja, implica a busca pela existência atrelada a uma referência espacial.

A Fenomenologia representa uma descrição do mundo vivido da experiência humana e, por meio da intencionalidade da consciência, reconhece as essências da estrutura perceptiva. A intencionalidade é compreendida como sendo o caminho pelo qual a consciência procura compreender o mundo (MARTINS, 1992). Assim, não haverá consciência sem o mundo e não existirá mundo sem a consciência. Isso ocorre de tal modo que todos os atos, gestos, ou qualquer ação humana auferem significado. Logo, a consciência é apreendida como atribuidora de significado para os objetos. Sem isso não se pode discorrer de objeto nem da essência do objeto.

Esta corrente filosófica procura decompor e interpretar a essência da consciência como resultado da percepção individual, onde os fenômenos não são 
compreendidos pela observação e avaliação de um espaço euclidiano, mas através do entendimento de um espaço vivido instigado por um sistema de relações e interações dos indivíduos com o ambiente (RELPH, 1979). Buttimer (1982) grifa a possiblidade de obter a experiência humana por meio do "mundo vivido", que na análise geográfica procura uma interação das pessoas com os lugares mediante a experiência vivida. Logo, o espaço vivido é uma construção social através da percepção e interpretação dos indivíduos, concretizando nas práticas sociais (TUAN, 1983). Ou seja, as experiências adquiridas por um indivíduo adquirem imensa importância nesta abordagem.

\subsection{ESTUDO DE CASO: CONJUNTO “MORADIAS BONILAURI”}

O conjunto habitacional "Moradias Bonilauri” está localizado no bairro Alto Tarumã, município de Pinhais, Estado do Paraná. O conjunto foi construído com o objetivo de reassentar mais de 600 famílias que moravam em situação de irregularidade às margens dos rios, sendo este o primeiro reassentamento de famílias de áreas de risco à inundação no município (SABBAG FILHO, 2006). O problema é que o "Moradias Bonilauri" é atingido constantemente por alagamentos e inundações, principalmente aqueles que aconteceram nos anos de 2003, 2009, 2010, 2011 e 2012 (FIGURA 01). 


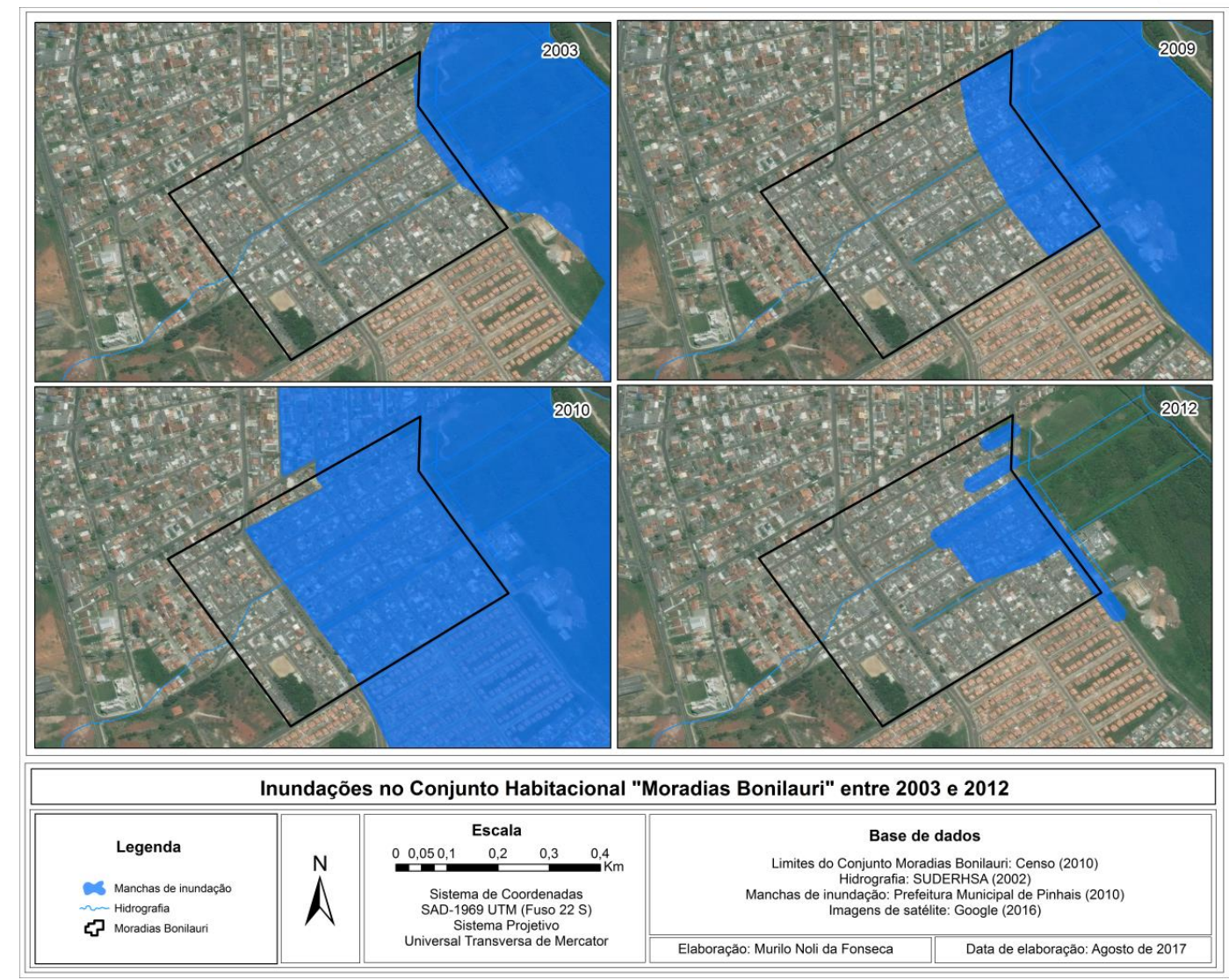

Hodiernamente, a população residente no Conjunto Habitacional "Moradias Bonilauri" apresenta uma baixa e homogênea situação socioeconômica. A maioria dos moradores encontra-se em estado de pobreza, com renda média de menos de um salário mínimo e nível de escolaridade que varia do analfabetismo ao ensino médio completo. Todas as moradias estão integradas à rede de esgoto, à coleta de lixo e são abastecidas por água (IBGE, 2010).

Todavia, a Coordenação da Região Metropolitana de Curitiba destaca que no terceiro ano após a implantação do conjunto havia uma elevada percentagem de famílias com renda entre um e dois salários mínimos, escolaridade equivalente ao ensino fundamental, $73 \%$ tinha acesso à escola, $69 \%$ a postos de saúde, $25 \%$ à rede de esgoto e 85\% à segurança pública (COMEC, 2001). Borges e Sabbag Filho (2001) asseguram que 40\% dos moradores reassentados para o Conjunto Habitacional "Moradias Bonilauri” não residiam mais nas unidades em 2001, $39 \%$ estavam satisfeitos com o reassentamento, $32 \%$ se mostravam indiferentes e $29 \%$ ressalvavam que suas condições haviam agravado. 
Revista Brasileira de História \& Ciências Sociais - RBHCS

Recentemente, o Conjunto passou por intervenções do poder público por meio do PAC-PPI-IF, sendo beneficiado pela regularização fundiária e urbanização. Isso aconteceu pela ocasião de que o "Moradias Bonilauri” era considerado um conjunto degradado, e as 688 unidades habitacionais não se encontravam regularizados, o que impedia a implantação de infraestruturas (COHAPAR, 2016).

\subsection{PRODUÇÃO DAS ENTREVISTAS DE PESQUISA}

Na etapa das entrevistas, a presidente da Associação de Moradores e Clube de Mães do Conjunto Habitacional, teve uma função primordial, pois foi por meio dela que se pôde ingressar em contato com os residentes do "Moradias Bonilauri" e com as lideranças. A partir dessa situação, os atores sociais colaboraram para outros contatos. A preocupação de ir ao local sem conhecer seus moradores e de ser uma área de violência foi ultrapassada neste processo.

A falta de intermédio poderia dar lugar ao risco de que os entrevistados não se sentissem confiantes para informar o que lhes era inquirido, atrapalhando o processo de aquisição das informações. Ou de que se sentissem inibidos de tal modo que não permanecessem à vontade para discorrer a respeito das suas histórias, das relações estabelecidas com o bairro e com o problema das inundações e seus impactos. Se por um lado o intermédio colaborou para promover uma relação de maior fidúcia com os atores sociais do conjunto, por outro, essas escolhas foram realizadas a partir de critérios eleitos pelos próprios intermediários. Cabe realçar ainda que alguns critérios foram postos a priori, como a quantidade de entrevistados, a idade e o número de pessoas de ambos os sexos. As entrevistas eram concretizadas em horários propostos pelas próprias lideranças, sobretudo em função de seu período de trabalho.

Para tanto, foi empregada a metodologia de entrevista reflexiva desenvolvida por Szymanski (2008), que consiste em uma entrevista semidirigida, realizada no mínimo em dois encontros, individual ou coletiva. Ela pode ser vista como aberta no sentido de basear-se na fala do entrevistado, mas os objetivos devem ser claros, assim como a informação que se ambiciona adquirir, a fim de se procurar uma compreensão do material que está sendo obtido e direcioná-la melhor. Essa metodologia apresenta três etapas 
fundamentais: o contato do pesquisador com a área de estudo e a população, à condução da entrevista, e a restituição da entrevista transcrita.

É imprescindível realçar que foram organizadas questões norteadoras e perguntas secundárias, conforme os objetivos da pesquisa. No entanto, não houve rigor no emprego deste roteiro, e as conversas foram realizadas no ritmo do entrevistado. É inegável que as questões inseridas no roteiro puderam ser sentidas no transcorrer da entrevista. Quando isso não acontecia, procedia-se às mesmas. Tal método permitiu que outras acepções subentendidas na conjuntura de uma conversa mais aberta fossem apreendidas. Na medida em que as informações dadas careciam de maiores detalhes, muitas vezes o entrevistado sugeria que se caminhasse no local para que fosse indicado como certas circunstâncias ocorriam.

Nesse sentido, as entrevistas foram semidirigidas e compostas por quatro perguntas norteadoras e semelhantes a todos os entrevistados:

1. Como chegou ao Conjunto Habitacional "Moradias Bonilauri"?

2. Como você vê as inundações?

3. O que elas provocam em sua vida?

4. O que poderia ser feito para minimizar e/ou solucionar as inundações?

A partir dessas interrogações e de acordo com o discurso do entrevistado, buscou-se, por meio da metodologia desenvolvida por Souza e Zanella (2010), compreender a percepção e a experiência do entrevistado em face o fenômeno analisado, a percepção quanto à causalidade e responsabilidade pelas inundações, entender a preferência por parte de alguns atores sociais pelo local de residência antes do reassentamento, e as estratégias desenvolvidas por estes e pelo poder público quantos aos riscos de inundação, bem como a ação e participação dos habitantes nas problemáticas socioambientais do Conjunto Habitacional "Moradias Bonilauri”. Além do que, a adoção da noção de Topofilia e Topofobia (TUAN, 2012) é fundamental para a compreensão que a população possui acerca do lugar onde estava vivendo antes do reassentamento e depois deste. 
Revista Brasileira de História \& Ciências Sociais - RBHCS

\subsection{CARACTERIZAÇÃO DOS ATORES SOCIAIS}

Foram entrevistados oito atores sociais, dos quais quatro mulheres e quatro homens, na faixa etária entre 35 e 65 anos, com escolaridade que varia do analfabetismo ao ensino médio completo, e com renda média por família entre um salário mínimo a quatro salários (QUADRO 1). As entrevistas foram concretizadas entre agosto e setembro de 2017.

As entrevistas realizadas, de distintas faixas etárias, gênero, escolaridade e renda, permitem observar que as percepções sobre o lugar de moradia, os riscos, os eventos hidrometeorológicos negativos e as medidas que visem a sua redução apresentam diferenças expressivas (DEL RIO, 1996). Por isso, há de se destacar, antes de qualquer coisa, o fato de que de todas os participantes não são naturais de Pinhais ou de algum município circunscrito a ele. Das oito pessoas entrevistadas, sete chegaram ao então Distrito de Pinhais entre as décadas de 1970 e 1980 e em apenas um caso na década de 2000 (já emancipado). Deste conjunto de entrevistados, quatro migraram do norte do Paraná e quatro da região oeste do Estado.

Quadro 1: Perfil dos atores sociais do "Moradias Bonilauri” entrevistados

\begin{tabular}{|c|c|c|c|c|c|}
\hline $\begin{array}{l}\text { Nome } \\
\text { fictício }\end{array}$ & Gênero & Idade & Escolaridade & $\begin{array}{l}\text { Renda média } \\
\text { familiar }\end{array}$ & $\begin{array}{c}\text { Ano de } \\
\text { chegada } \\
\text { a Pinhais }\end{array}$ \\
\hline Liderança 1 & Feminino & 65 anos & Analfabetismo & 1 salário mínimo & 1970 \\
\hline Liderança 2 & Feminino & 42 anos & $\begin{array}{l}\text { Fundamental } \\
\text { Incompleto }\end{array}$ & $\begin{array}{l}2 \text { salários } \\
\text { mínimos }\end{array}$ & 1989 \\
\hline Liderança 3 & Feminino & 37 anos & Fundamental completo & $\begin{array}{l}3 \text { salários } \\
\text { mínimos }\end{array}$ & 1992 \\
\hline Liderança 4 & Feminino & 53 anos & $\begin{array}{c}\text { Fundamental } \\
\text { Completo }\end{array}$ & $\begin{array}{l}3 \text { salários } \\
\text { mínimos }\end{array}$ & 1984 \\
\hline Liderança 5 & $\begin{array}{c}\text { Masculin } \\
\text { o } \\
\end{array}$ & 62 anos & $\begin{array}{l}\text { Fundamental } \\
\text { Incompleto }\end{array}$ & $\begin{array}{l}2 \text { salários } \\
\text { mínimos }\end{array}$ & 2004 \\
\hline Liderança 6 & $\begin{array}{l}\text { Masculin } \\
\text { o }\end{array}$ & 46 anos & $\begin{array}{l}\text { Fundamental } \\
\text { Incompleto }\end{array}$ & 2 salário mínimo & 1978 \\
\hline Liderança 7 & $\begin{array}{l}\text { Masculin } \\
0\end{array}$ & 35 anos & Médio Completo & $\begin{array}{l}\text { 4 salários } \\
\text { mínimos }\end{array}$ & 1985 \\
\hline Liderança 8 & $\begin{array}{c}\text { Masculin } \\
\text { o } \\
\end{array}$ & 58 anos & $\begin{array}{l}\text { Fundamental } \\
\text { Incompleto }\end{array}$ & 1 salário mínimos & 1976 \\
\hline
\end{tabular}

Com exceção da Liderança 5, que chegou à Pinhais em 2004, os outros atores sociais migraram do interior do Estado do Paraná em um momento no qual havia um processo de modernização da agricultura. Essa modernização resultou em uma circunstância de êxodo rural, onde Curitiba passou a ser um celeiro de empregos, especialmente com o estabelecimento de empresas dos 
Revista Brasileira de História \& Ciências Sociais - RBHCS

Acadêmicos \& Pesquisas

Vol. $12 \mathrm{~N}^{\circ} 23$, Janeiro - Junho de 2020

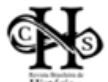

setores secundário e terciário da economia, o que serviu como polo de atração para essa população. Todavia, o alto custo da terra na capital paranaense se tornou um empecilho para o estabelecimento dessas pessoas, restando-as a ocupar as áreas mais acessíveis financeiramente, ou seja, as de alta suscetibilidade natural, sobretudo as inundáveis e voltadas à proteção ambiental, devido aos principais mananciais de abastecimento da RM

Nesse processo, a Liderança 1 narra que migrou do município de Jacarezinho, norte do Paraná, para Pinhais em 1970, porque seus pais, que trabalhavam com a agricultura, buscavam melhores condições de vida em Curitiba. No entanto, pela ocasião de não conseguirem adquirir um terreno ou pagar uma locação na capital paranaense, restou a ela e a seus pais ocuparem o lugar mais acessível financeiramente à época. Destaca-se que ela viveu em dois locais com distintas exposições ao risco de inundações: o primeiro em um domicílio situado no mesmo nível da confluência dos rios Atuba e Iraí entre 1970 e 1983, no bairro Weissópolis, e a segunda em uma área mais ao norte, na beira do Rio Palmital, no bairro Vargem Grande, próximo à Avenida Ayrton Senna, entre 1983 e 1998. Nesse caso, a habitação encontrava-se em uma parte mais elevada do terreno, ou seja, apresentava uma menor exposição ao risco de inundações. Tal mudança aconteceu principalmente pela opção de não pagar mais aluguel.

Essa conjuntura é semelhante com a história da Liderança 2, que migrou do município de Bandeirantes, norte do Paraná, para Pinhais em 1989. Inicialmente, ela e seus pais buscavam melhores condições de vida em Curitiba, todavia foram morar de aluguel na margem do Rio Palmital, no bairro Jardim Cláudia. Não obstante, essa preferência pelo local de moradia não foi espontânea, deve-se a uma necessidade atribuída as condições socioeconômicas. Por outro lado, a Liderança 7 migrou de Cascavel, oeste do Paraná, para Pinhais em 1985. Primeiramente, ela e sua família foram residir em uma casa de aluguel no Weissópolis. Eles permaneceram neste local até 1990, quando a sua mãe decide cessar o aluguel e opta por comprar um direito na beirada do rio, ou seja, uma área de ocupação irregular. Isso evidencia a situação de precariedade infraestrutural em um ambiente plano, próximo a um rio, com solos 
Revista Brasileira de História \& Ciências Sociais - RBHCS

hidromórficos e área de manancial, o que implica em uma maior exposição e vulnerabilidade aos riscos.

Já a Liderança 4 descreve que migrou primeiramente de Londrina, no norte do Paraná, para Rio Branco do Sul, em 1982, onde seu cônjuge era guardião de um posto, e deste município para Pinhais, no bairro Jardim Cláudia, em 1984. Tal mudança aconteceu, principalmente, pois almejava, junto com o seu esposo, oferecer melhores condições de estudo para os filhos e tinha aversão de enviá-los ao colégio onde residiam, uma vez que teriam que atravessar a rodovia BR-116. E a preferência pelo local da moradia foi baseada, de maneira especial, pelo custo do terreno e da proximidade com uma escola.

Em linhas gerais, apreende-se que a ocupação do ser humano em áreas com alta fragilidade ambiental, como as planícies de inundações, resulta de uma escolha forçada e não voluntária, e provoca profundas transformações na rede de drenagem, gerando invariavelmente de modo mais frequente casos de inundação (TUCCI, 2003). Mas, é imprescindível salientar que essa circunstância perpassa necessariamente pela situação financeira, que se torna cada vez mais um dos principais motivos que impedem os indivíduos de residirem em áreas apropriadas para a ocupação e com menor ou nula exposição ao risco e a vulnerabilidade ambiental. Além do mais, observa-se que as próprias pessoas reconhecem que habitavam uma área de risco.

Assim, as áreas mais acessíveis aos grupos de baixa renda são, na maioria das vezes, consideradas como inadequadas para a ocupação, o que suscita um acréscimo de ocupações precárias, como as favelas e loteamentos irregulares, atreladas a deficiências infraestruturais e, por essa razão, exibem uma maior exposição e vulnerabilidade aos riscos (ALVES, 2007).

\section{RESUTADOS}

5.1. TOPOFILIA, TOPOFOBIA E O ESPAÇO VIVIDO NO "MORADIAS BONILAURI"

Faz-se necessário apreender como os entrevistados percebem holisticamente o "Moradias Bonilauri”. Para tanto, será empregado como conceitos norteadores o de "Topofilia", as experiências mais agradáveis da paisagem, e de “Topofobia”, que é o oposto, ou seja, as "paisagens do medo". Ao 
Revista Brasileira de História \& Ciências Sociais - RBHCS

serem questionados sobre as vantagens de localização no "Moradias Bonilauri”, no intuito de compreender o motivo que os levam a permanecer em uma área de risco, ficaram comprovadas nos depoimentos de seis pessoas as questões afetivas e as experiências agradáveis do convívio no local, isto é, o espaço vivido pelos moradores e, por essa razão, não sentem pretensão de alterar o local de moradia (TUAN, 2012).

Esse tipo de sentimento é até disparatado quando se considera que essa população reconhece os problemas e perigos da sua comunidade, porém essa sensação de pertencimento e afabilidade ao "Moradias Bonilauri" acaba se sobrepondo aos múltiplos problemas já elencados anteriormente, como é a própria questão da "naturalidade" do crime, da vulnerabilidade às inundações e a inexistência dos títulos de propriedade de seus imóveis. Em circunstâncias como essa não se deve avaliar exclusivamente os aspectos racionais, mas também as identidades e os simbolismos construídos em torno dos lugares que, apesar de apresentarem características de degradação econômica, social ou ambiental, mantém a sua capacidade aglutinadora e de atração para a população (MARANDOLA JR.; HOGAN, 2005).

Dentre as vantagens elencadas, destaca-se: boa acessibilidade a serviços básicos, como de saúde, escola, ônibus, entre outros; a boa relação que se estabelece com os vizinhos; o fato de estar próxima de familiares; a dependência recíproca entre os próprios moradores; e a não ocorrência de inundações desde 2014. A partir dos exemplos apresentados pelos participantes, apreende-se que a importância das relações afetuosas entre os próprios moradores e familiares contribuem para amenizar os inconvenientes do ambiente onde vivem. Essa construção e interação social está relacionada ao compartilhamento de experiências. "A cultura é indispensável ao indivíduo no plano de sua existência material. Ela permite sua inserção no tecido social. Dá uma significação à sua existência e a dos seres que o circundam e formam a sociedade da qual se sente membro" (CLAVAL, 2007, p. 89). Ou seja, pode-se assegurar que esses indivíduos se sentem pertencentes ao lugar.

É possível observar o pertencimentos nos depoimentos, como na Liderança 6, que salienta que apesar de alguns problemas, como a questão da adaptabilidade das calçadas para pessoas com deficiência visual e física, adora 
Revista Brasileira de História \& Ciências Sociais - RBHCS

viver no "Moradias Bonilauri", pois considera ser um bairro tranquilo, com infraestrutura, uma vizinhança boa, e sobretudo, porque não precisa pagar aluguel. A Liderança 8 faz referência ao fato de que além do lugar ser tranquilo, o posto de saúde, os pontos de ônibus e a creche são perto do conjunto habitacional, e se fosse para ter melhorias, deveria ser instalada uma escola mais próxima e uma academia ao ar livre.

Por outro lado, é importante frisar que considerações pertinentes à afetividade e ao convívio que a população tem com os moradores e com o seu lugar devem ser consideradas quando da intervenção em seus espaços. Tais questões podem esclarecer porque, frequentemente, os reassentamentos são mal sucedidos e as pessoas retornam para o lugar de onde foram deslocados. A Liderança 2, embora não tenha sido reassentada da área de risco no Jardim Cláudia para o Bonilauri, vivenciou tal situação com a sua avó. Por isso, ela afirma que o "Bonilauri" foi construído de um jeito errado, pois não pensaram na localização dos terrenos ou serviços básicos, como uma escola. E frisa que não há nada bom a dizer sobre essa situação, de ser "jogado" em um ambiente sem planejamento. Apenas o que salva, é que os outros moradores ajudam como podem.

Em contrapartida, a Liderança 1 foi a única das pessoas reassentadas que não fizeram referência a experiências agradáveis no "Bonilauri”. Conforme ela, o lugar em que vive é horrível, pois já teve a experiência de viver em outras regiões, e considera que esse condomínio é a pior de todas. Como exemplo, ela relembra quando foram realocados, onde viviam em 6 pessoas em uma casa de 60 metros quadrados, e fizeram eles se mudarem para uma de 19,5 metros quadrados. Atualmente, a casa é maior porque eles tiveram de construir com o dinheiro do próprio bolso, destacando que foi prejuízo se mudar, pois antes tinham uma casa, e deram um "barraco" para viverem.

Outro ponto que a Liderança 1 afirma é que nunca foi atingida por uma inundação no lugar em que morava, enquanto que no "Bonilauri" isso sempre acontece. Ou seja, o poder público ao retirar as pessoas de uma área de risco e colocá-las em um conjunto habitacional, mas em uma área inadequada para a ocupação, de alta fragilidade ambiental às inundações e sem uma infraestrutura adequada para a redução da ocorrência de inundações e minimização das 
Revista Brasileira de História \& Ciências Sociais - RBHCS

Acadêmicos \& Pesquisas

Vol. $12 \mathrm{~N}^{\circ} 23$, Janeiro - Junho de 2020

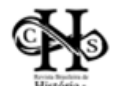

consequências associada a elas durante um hiato de 13 anos (1998-2011), acabou por inseri-las em uma situação de alta vulnerabilidade socioambiental, especialmente ao risco de inundações. Dessa maneira, a Liderança 1, embora resida no "Moradias Bonilauri” desde o seu início em 1998, não se adaptou às condições adversas desse ambiente. Por isso, é uma pessoa que não se sente inserida e pertencente ao lugar e, se pudesse se instalaria em outros locais.

Observa-se que as experiências das pessoas ocorrem de maneira singular, de tal modo que cada participante possui sua própria percepção a partir de sua vivência anterior. Essa construção social e cultural de cada indivíduo perpassa pelas relações do espaço e ambiente. "A dinâmica da cultura depende de crenças, convicções e comportamentos que são adquiridos. $\mathrm{O}$ estudo dos processos por meio dos quais a cultura é transmitida implica que nos interessemos, antes de tudo, pelas relações individuais” Claval (2007, p.145).

\subsection{CONSEQUÊNCIAS E PREJUÍZOS DAS INUNDAÇÕES}

Adiciona-se a essa conjuntura - das consequências e prejuízos -, os múltiplos estragos provocados pelas inundações, sejam eles danos nas moradias, especialmente em relação a móveis, e avarias na estrutura da casa. Cabe destacar que os impactos e os prejuízos não acontecem de forma homogênea no espaço, de modo que se constatam similitudes entre as áreas de suscetibilidade natural (áreas planas e próximas a rios) e as de vulnerabilidade social (CUNICO, 2013). Encontram-se também intrinsecamente relacionadas com a localização da moradia, o grau de exposição ao risco, à prevenção e as próprias características dos eventos. Por essa razão, das pessoas entrevistadas que habitavam áreas de alta suscetibilidade natural, somente duas relataram não terem sido atingidas por inundações.

Em contrapartida, as pessoas entrevistadas que habitavam a margem de um rio reconhecem que se encontravam em uma área sujeita ao risco de inundações e expunham uma vulnerabilidade. Essa circunstância expressa uma condição de vulnerabilidade socioambiental a que os entrevistados estavam submetidos. E apenas quatro apresentavam uma experiência espacial e corporal direta com o fenômeno, enquanto que as outras duas somente de forma indireta. 
Segundo Claval (2007), as diferentes culturas e vivências são influenciadas pelos seguintes pontos principais:

1. Relação entre o homem e a natureza, buscando o equilíbrio a partir dos conhecimentos adquiridos;

2. Maneira como grupos sociais lidam com o ambiente, aproveitando ao máximo as tecnologias e o uso sustentável;

3. Experiências passadas de pai para filho, sendo a comunicação o instrumento principal de compartilhamento de informação;

4. Lideranças, com a representação do espaço ou de grupos sociais perante a sociedade;

5. Infraestruturas e construções que se modificam a partir das preferencias locais;

6. Status social, tendo em vista que nem todas as pessoas possuem as mesmas oportunidades.

Observa-se que para o autor, a construção cultural perpassa pela representação dos diferentes grupos sociais, sendo fortalecida pelas experiências adquiridas das pessoas no ambiente em que vivem. Com base nisso, cabe as seguintes indagações:

As experiências influenciam de alguma maneira no comportamento individual e/ou coletivo e/ou no desenvolvimento de alguma medida de resposta/adaptação, que visasse à redução do risco? E no caso das pessoas que apresentavam exclusivamente uma experiência indireta? Houve o desenvolvimento de alguma medida de prevenção? Ou a consciência de que a inundação não representava uma ameaça inibiu tal desenvolvimento? E o poder público? Será que as pessoas perceberam a presença ou ausência dele na implantação de estratégias para reduzir a o risco e a ocorrência de inundações e minimizar ou até mesmo extinguir as decorrências associadas a tais? Se sim, foram concretizadas de forma eficaz ou agravaram a situação? Esses questionamentos são primordiais para uma melhor compreensão sobre a percepção dos indivíduos perante o risco de eventos hidrometeorológicos negativos.

Faz-se imprescindível apreender como os entrevistados percebem as consequências e os prejuízos desencadeados pelas inundações ocorridas no "Moradias Bonilauri”. As consequências e prejuízos estão intrinsecamente relacionados com a localização e a condição da moradia, a vulnerabilidade, o grau de exposição ao risco, a prevenção e próprias características dos eventos. Todos 
Revista Brasileira de História \& Ciências Sociais - RBHCS

Acadêmicos \& Pesquisas

Vol. $12 \mathrm{~N}^{\circ} 23$, Janeiro - Junho de 2020

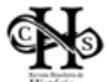

os entrevistados relatam que junto com as inundações decorriam os mais distintos elementos, sobretudo a violência e o lixo, o que corrobora o apontamento de alguns entrevistados, quando asseguram que o lixo é uma das principais causas de inundações no "Bonilauri”.

Os dois atores sociais que relataram não terem sido atingidos por inundações, curiosamente são os mesmo que não foram reassentadas da área de risco para o conjunto habitacional. No entanto, essa afirmativa só é válida para o interior da casa, uma vez que, conforme esses entrevistados, o terreno, as ruas e os vizinhos eram atingidos com frequência. Em outras palavras, a ausência de ameaças, de prejuízos materiais e de experiência pode influenciar o desenvolvimento de estratégias de prevenção, já que para o ser humano reagir é preciso sentir-se ameaçado (ABREU; ZANELLA, 2015).

Por outro lado, as outras lideranças, das quais cinco foram reassentadas, descreveram que foram atingidas inúmeras vezes por inundações, especialmente por possuírem a habitação no mesmo nível da rua, até mesmo aquelas que haviam narrado que não haviam sido atingidas no lugar em que moravam. Apreende-se uma crença de que o reassentamento de uma área de risco para um conjunto habitacional resultaria em uma menor ou nula exposição ao risco e, por essa razão, não seria necessário desenvolver medidas de prevenção ao risco de inundações. Essa contrariedade entre as percepções dos que são ou não atingidos por inundações, apresenta como a cultura de cada cidadão, é construída por meio do que é vivenciado (CLAVAL, 2010).

Destarte, observa-se nenhuma ação de prevenção a esses eventos, mesmo reconhecendo que habitam uma área sujeita ao risco. A ocorrência de tais eventos no "Moradias Bonilauri” foi imprevista para essas pessoas, já que as inundações pegaram todos de surpresa. Apreende-se também que as pessoas conferem ao poder público a responsabilidade pela vulnerabilidade ao risco de inundações, isto é, o reassentamento tornou-se uma transferência de risco. Segundo a Liderança 8, o poder público os garantiu que o reassentamento teve o objetivo de tirar essas pessoas das margens do rio para que elas tivessem uma melhor qualidade de vida em um local onde não teria mais inundações. Já a Liderança 2 afirma que no bairro Cláudia, onde moravam, eles nunca tiveram nenhuma ocorrência de inundação em suas casas, mas após se mudarem para o "Moradias 
Revista Brasileira de História \& Ciências Sociais - RBHCS

Bonilauri”, perderam muitas coisas várias vezes devido a frequências das cheias do rio. Ela ainda destaca que a água era misturada com barro e chegava a atingir 40 centímetros dentro da casa, sendo a velocidade da cheia muito alta, não dando para salvar nada.

A Liderança 1 afirma que o governo retirou essas pessoas das margens do rio, mas o lugar que escolheram para reassentá-las foi o "braço-do-mar" devido à altura que a água consegue alcançar. Para ela, é perceptível que o local era um banhado, uma área de manancial e que por isso, todos sabiam que era uma região de inundação. Inclusive, várias reportagens já haviam sido vistas na rede de televisão de áreas próximas ao "Moradias Bonilauri”, e mesmo que ela afirmasse aos responsáveis pelo reassentamento que haveria inundação na residência escolhida para ela, eles insistiram que ela poderia se mudar sem preocupação e que qualquer coisa dariam uma nova casa a ela. Não sendo concretizada mais esta promessa.

Além do mais, há um elemento físico-natural que agrava a circunstância das inundações no "Moradias Bonilauri”, especialmente na casa da Liderança 1. Dentro da sua residência, na sala, têm cinco nascentes de água. Isto faz com que a água entre dentro dos outros cômodos, prejudicando os revestimentos da casa, que se soltam devido ao inchaço provocado pela humidade, e ainda mais grave, prejudicam a estrutura da casa de forma geral.

Adiciona-se a isso as múltiplas perdas suscitadas pelas inundações, sejam eles problemas de saúde, avarias nas residências, sobretudo em relação a móveis, roupas, eletrodomésticos, e detrimentos na estrutura da casa. A Liderança 4 afirma que as pessoas perdem tudo da casa diversas vezes, pois não há tempo de erguer nada para salvar. Essa situação se dá ou pela velocidade da inundação ou porque ela acontece durante a noite, então as pessoas acordam com a casa cheia de água. Os comércios próximos ao conjunto habitacional também têm prejuízos altos, pois com a entrada da água, muitas mercadorias se perdem, como papéis higiênicos, frios e carnes (Liderança 2). Embora não tenha sido atingido, a Liderança 6 faz referência ao momento posterior as inundações. Ele conseguiu ver os estragos que as pessoas tiveram de arcar, com os móveis, eletrodomésticos, roupas e colchões sendo jogados fora. 
A última inundação que afetou o conjunto habitacional teve bastante impacto. Foram três dias em que as pessoas tiveram que lidar com a água e o barro dentro de suas casas à um metro de altura. Não havia onde dormir e o único jeito de sair de casa era nadando. Foi perdido todos os móveis, os eletrodomésticos, utensílios e comida. As pessoas já não têm quase nada, e toda vez que acontece as cheias do rio, perdem o pouco que tem. Se não forem as doações, ninguém tem nada (Liderança 1).

Outro problema descrito pela maior parte dos entrevistados se relaciona à saúde das suas famílias e da vizinhança. Dentre eles, destacam-se a leptospirose, a dengue e a pneumonia. A Liderança 2 narra a ocorrências de múltiplos casos de leptospirose no "Moradias Bonilauri", mas destaca que a dengue foi a que mais afetou a região, pois quando chove, muitas poças se formam no banhado. Por essa razão, diversas famílias precisam ir para o hospital. Já a Liderança 1 descreve a ocorrência de casos de pneumonia e leptospirose, sendo que em um dos eventos houve um óbito pela contaminação. Ela também salienta que já contraiu pneumonia na inundação ocorrida no ano de 2010, pelo fato de ter permanecido três dias em contato com a água suja, com barro e esgoto sem poder sair de casa. A Liderança 1 ainda afirma que já chegou a tomar banho de álcool com medo de pegar alguma doença decorrente das inundações.

Não foram feitas referências apenas a problemas de saúde, danos na moradia e na sua própria estrutura, mas também casos de óbito. A Liderança 5 assegura que a uma pessoa morreu em 2010 e não se tem certeza se ela já estava doente, ou devido a inundação, ela não conseguiu sair. Só a encontraram depois de alguns dias boiando na água. A Liderança 1 lembra que já teve até bebê que se afogou dentro do próprio berço que a mãe não conseguiu tirar. A Liderança 2 menciona outro caso, no qual um senhor estava andando na calçada e acabou caindo em uma valeta, de barriga para baixo. Até a família localizar, o homem já havia morrido na água.

Logo, ao serem indagados a respeito do sentimento que apresentaram durante uma inundação, há uma combinação de raiva, angústia, tristeza, frustração, descaso do poder público, abandono e vontade de ir embora. E das três pessoas que não foram reassentadas da área de risco para o "Moradias Bonilauri”, duas relatam que sentiram frustação, principalmente com a ocorrência do fenômeno em si, ou seja, com as inundações, pois a Liderança 6 afirma que quando compraram a casa, eles acreditavam que não aconteceria 
Revista Brasileira de História \& Ciências Sociais - RBHCS

enchentes. Por isso, algumas pessoas citam que pensam em vender a casa e sair dali (Liderança 5).

Por outro lado, no caso das pessoas que foram reassentadas da área de risco há um sentimento de descaso e abandono por parte do poder público, devido aos inúmeros problemas presentes. Por exemplo, até pouco tempo atrás, havia uma valeta bem no meio da rua (Liderança 2). E essas pessoas pagam por uma coisa que não recebem. Todo mês devem pagar os impostos, como o IPTU. E mesmo assim o governo só faze promessas e não cumprem nada (Liderança 7). Além do mais, a Liderança 8, reassentada da beira do Rio Atuba, assegura que mesmo que tenha perdido muita coisa enquanto morava na outra casa, ela sente muita raiva por ter sido reassentada em um local em que está perdendo tudo também. Já a Liderança 2 descreve que tinha vontade de sair e abandonar tudo, contudo, do mesmo modo, não tem como sair sem vender, pois não tem como comprar outra coisa.

Por causa dessa situação, percebe-se o relato não somente de danos materiais, mas também psicológicos, cicatrizes emocionais deixadas pelo trauma vivido. As pessoas não dormem mais a noite, só após as cinco horas da manhã, pois a noite estão sempre em alerta, assombradas pelas enchentes, principalmente em dias de chuva (Liderança 1). A Liderança 2 também cita um caso pessoal familiar, em que sua avó caiu em depressão, porque ela não queria sair de onde eles estavam. A única razão por terem se mudado foi por não ter para onde ir, se não teriam feito como muitas outras pessoas fizeram, voltariam para o mesmo lugar em que foram retiradas (Liderança 2).

As transformações vivenciadas pelas pessoas, associadas às pressões e aos choques culturais e sociais em que estão submetidas, fazem parte da compreensão da geografia humana. As relações e experiências vivenciadas entre o homem e o ambiente, proporcionam o autoconhecimento e a orientação no espaço (CLAVAL, 2007).

Portanto, os indivíduos que passam por eventos extremos sofrem expressivos impactos na saúde mental, o que as tornam atribuladas pelo temor e pela consternação de que o evento possa ocorrer outra vez ou pela aflição de perder bens materiais, afetivos e pessoas próximas (SÁ et al., 2008). Já Steiner et al. (2013) revelam que estudos têm indicado que $75 \%$ das pessoas expostas a uma 
Revista Brasileira de História \& Ciências Sociais - RBHCS

Acadêmicos \& Pesquisas

Vol. $12 \mathrm{~N}^{\circ}$ 23, Janeiro - Junho de 2020

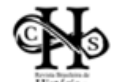

situação traumática devem ser avaliadas quanto à possibilidade de exibirem distúrbios psíquicos com morbidades adjuntas. Por isso, Reichert (2011) realça a importância da função da psicologia nessa circunstância, de modo que a atuação de profissionais habilitados e com o incremento de arquétipos de intervenção através de técnicas de comunicação e mutação de condutas possibilitem a oferta de ajuda em situações de impacto e perigo.

\section{CONCLUSÃO}

Os prejuízos decorrentes das inundações e os riscos são percebidos pela maioria dos atores sociais, sobretudo aqueles que foram reassentados da área de risco para o "Moradias Bonilauri”. Esta situação varia ainda mais pelo fato de algumas pessoas morarem por imposição em ruas com um grau maior de exposição ao risco do que outras pessoas, como é a Avenida Porto Alegre e a Avenida Porto Velho, devido aos dois afluentes do Rio Palmital que hoje encontram-se manilhados. Esta circunstância ocorreu também em razão de possuírem a moradia no mesmo nível da rua, inclusive aqueles que haviam narrado não serem atingidos no lugar em que moravam. Em outras palavras, apreende-se uma crença de que o reassentamento de uma área de risco para um conjunto habitacional resultaria em uma menor ou nula exposição ao risco e, por essa razão, não seria necessário adotar medidas de prevenção às inundações. Ou também como fruto da crítica vulnerabilidade socioeconômica a que estão submetidas.

No momento prévio ao reassentamento, quando a preferência pelo local de moradia era determinada por questões financeiras não havia a consciência de que a ocupação em uma área de alta fragilidade ambiental era a essência da questão das inundações. Todavia, a partir da ocasião em que o poder público retira as pessoas da área de risco e as assenta em um conjunto habitacional, localizado também numa área de alta fragilidade ambiental e sem uma infraestrutura apropriada, com o pressuposto de que não permaneceriam expostos ao risco de inundação, mas que desde a sua introdução no Bonilauri 
Revista Brasileira de História \& Ciências Sociais - RBHCS

Vol. $12 \mathrm{~N}^{\circ} 23$, Janeiro - Junho de 2020

foram atingidas inúmeras vezes e sofridos múltiplos detrimentos, passa-se a ter uma consciência a respeito da relação entre a ocupação e tais eventos.

Quando arguidos sobre o que poderia ser feito no "Moradias Bonilauri" para minimizar e/ou resolver o problema das inundações, a maior parte dos atores sociais arrogam ao poder público o desenvolvimento de estratégias de resposta. Isto pode representar a desinformação e o baixo nível de consciência da importância no processo de minimização das inundações, além da ausência de incentivo coletivo à participação e ao envolvimento da população na gestão municipal e dos riscos. Logo, as medidas que deveriam ser tomadas pelo poder público são estruturais, o que sugere certa eficácia de tais medidas ou o desconhecimento de outras formas de minimização das inundações.

O presente trabalho se revelou como um importante instrumento na compreensão prática da relação entre o ser humano e o meio ambiente, ainda mais para estudos sobre os riscos e vulnerabilidades socioambientais, e, dessa maneira, para o planejamento e gestão do espaço urbano e aperfeiçoamento de uma gestão dos riscos às inundações.

\section{REFERÊNCIAS BIBLIOGRÁFICAS}

ABREU, Nair Júlia Andrade de; ZANELLA, Maria Elisa. Percepção de risco de inundações: estudo de caso no bairro Guabiraba, Maranguape-Ceará. Revista OKARA: Geografia em debate, v.9, n.1, p.90-107, 2015.

ALVES, Humberto Prates da Fonseca. Desigualdade ambiental no município de São Paulo: análise da exposição diferenciada de grupos sociais a situações de risco ambiental através do uso de metodologias de geoprocessamento. Revista Brasileira de Estudos de População, São Paulo, v.24, n.2, p. 301-306, 2007.

ANDRADE, Manoel Correia de. Geografia, ciência da sociedade: uma introdução à análise do pensamento geográfico. São Paulo: Atlas, 1987. BERENT, Stanley. Psicologia introdutória: manual básico de autoinstrução. Trad. Rossine Fernandes. São Paulo: Editora Cultrix, 1981. BORGES, Luciana; SABBAG FILHO, Omar. Reassentamentos Humanos em Programas de Recuperação de Mananciais sob a ótica do Desenvolvimento Sustentável. Monografia (I Concurso de Monografias Desenvolvimento Sustentável no Paraná: Uma realidade Possível?) Núcleo Interdisciplinar de Meio Ambiente e Desenvolvimento (NIMAD), Universidade Federal do Paraná, Curitiba, 2001.

BUTTIMER, Anne. Aprendendo o dinamismo do mundo vivido. In:

CHRISTOFOLETTI, António. (Org.). Perspectivas geográficas. São Paulo: DIFEL, 1982. 
Revista Brasileira de História \& Ciências Sociais - RBHCS Vol. $12 \mathrm{~N}^{\circ} 23$, Janeiro - Junho de 2020

CLAVAL, Paul. A geografia cultural. Tradução de Luiz Fugazzola Pimenta e Margareth de Castro Afeche Pimenta. 3 ed. Florianópolis: Editora da UFSC, 2007.

CLAVAL, Paul. O Papel da Nova Geografia Cultural na Compreensão

da Ação Humana. In: CORREAA, Roberto Lobato; ROSENDAHL, Zeny. (Org.). Matrizes da Geografia Cultural. Rio de Janeiro: EdUERJ, 2001. p. 35-86.

CLAVAL, Paul. Terra dos Homens: a geografia. Tradução Domitila

Madureira. São Paulo: Contexto, 2010.

COHAPAR. Companhia de Habitação do Paraná. Plano Estadual de

Habitação de Interesse Social - área de conjunto habitacional degradado.

Paraná, 2016. (Relatório)

COMEC. Coordenação da Região Metropolitana de Curitiba. Relatório

PROSAIM 2001. Curitiba, 2001.

CUNICO, Camila. Do risco à adaptação: a identificação da vulnerabilidade socioambiental de Curitiba - PR. Tese (Doutorado) Programa de Pós-graduação em Ciências da Terra, Universidade Federal do Paraná, Curitiba, 2013

DARDEL, Eric. L'Homme et la terre: nature de la realite geographique.

Paris: Presses Universitaires de France, 1952. 133p

DEL RIO, Vicente. Cidade da Mente: Cidade Real. In: OLIVEIRA, Livia de; DEL RIO, Vicente (org.). Percepção Ambiental: a experiência Brasileira. São Paulo: Studio Nobel, Universidade Federal de São Carlos, 1996, p. 3-22. EM-DATA. Emergency Events Database. Disaster Year in Review 2019. UCLouvain, USAID, CRED, 2020. Disponível em: http://www.em-dat.net/, acesso em: 30/05/2020.

GUHA-SAPIR, Debby; VOS, Femke; BELOW, Regina; PONSERRE, Sylvain. Annual Disaster Statistical Review 2011: the numbers and trends. CRED, Bruxelas, 2012. (Relatório).

IBGE. Instituto Brasileiro de Geografia e Estatística. Censo 2010. Disponível em: https://censo2010.ibge.gov.br/, acesso em: 10/12/2019.

KOBIYAMA, Masato; CHECCHIA, Tatiane; SILVA, Roberto Valmir; SCHRÖDER, Paulo Henrique; GRANDO, Ângela; REGINATTO, Gisele Marilha Pereira Papel da comunidade e da universidade no gerenciamento de desastres naturais. In: Simpósio Brasileiro de Desastres Naturais, 2004. Florianópolis/SC. Anais... Florianópolis/SC: GEDN/UFSC, 2004. p.834-846.

LEOPOLD, Luna Bergere, WOLMAN, M. Gordon, MILLER, John. Fluvial processes in geomorphology. San Francisco: Freeman and Co. 1964. MACHADO, Lucy Marion Calderini Philadelpho. Reflexões sobre a abordagem perceptiva no estudo da paisagem. Geografia, v.11, n.21, p.143-146, 1983.

MARANDOLA JR., Eduardo; HOGAN, Daniel Joseph. Natural hazards: o estudo geográfico dos riscos e perigos. Ambiente e Sociedade, v.7, n.2, p.95110, 2004.

. Vulnerabilidade e riscos: entre geografia e

demografia. Revista brasileira de estudos populacionais: São Paulo, v.22, n.1, p.29-53, 2005 .

MARTINS, Joel. Um enfoque fenomenológico do currículo: educação como poíesis. São Paulo: Cortez, 1992.

MERLEAU-PONTY, Maurice. Fenomenologia da Percepção. São Paulo:

Martins Fontes, 1994. 
Revista Brasileira de História \& Ciências Sociais - RBHCS Vol. $12 \mathrm{~N}^{\circ}$ 23, Janeiro - Junho de 2020

MONTEIRO, Ana. Riscos climáticos, hazards, áleas, episódios extremos. In: AMORIM, Margarete; SANT'ANNA NETO, João Lima; MONTEIRO, Ana. (Orgs.). Climatologia urbana e regional: questões teóricas e estudos de caso. 1. Ed. São Paulo: Outras Expressões, p. 143-171, 2013.

OLIVEIRA, Lívia. Percepção da Paisagem Geográfica: Piaget, Gibson e Tuan. Geografia, Rio Claro, v. 25, n.2, p.5-22, 2000.

OLIVEIRA, Lívia; MACHADO, Lucy Marion Calderini Philadelpho. Percepção, cognição, dimensão ambiental e desenvolvimento com sustentabilidade. In: VITTE, Antônio Carlos; GUERRA, Antônio José Teixeira (Orgs.). Reflexões sobre a geografia física no Brasil. Rio de Janeiro: Bertrand Brasil, 2004, p.129-152.

RELPH, Edward. As Bases Fenomenológicas da Geografia. Geografia. v. 4, n. 7, p.1-25, 1979.

SABBAG FILHO, Omar. Diretrizes para a recuperação e conservação ambiental de mananciais de abastecimento de água comprometidos por ocupações irregulares. Dissertação (Mestrado), Universidade Federal do Paraná - UFPR, Curitiba, PR, 2006.

SARTORI, Maria da Graça Barros. Clima e percepção em geografia:

Fundamentos teóricos - A percepção climática e a bioclimatologia humana.

Santa Maria, 2014.

SZYMANSKI, H. Entrevista reflexiva: um olhar psicológico sobre a entrevista em pesquisa. In: SZYMANSKI, H.; ALMEIDA, L. R.; PRANDINI, R. C. A. R. A Entrevista na pesquisa em educação: a prática reflexiva. Brasília: Liber Livro, 2008.

TEIXEIRA, Salete Kozel. Das Imagens à Linguagem do Geográfico:

Curitiba a "Capital Ecológica”. Tese (Doutorado), Universidade de São Paulo USP, São Paulo, SP, 2001.

TUAN, Yi-Fu. Geografia Humanística. In: CHRISTOFOLETTI, A. (org.).

Perspectivas da Geografia. São Paulo: Difel, 1982. p.143-164. . Espaço e lugar: a perspectiva da experiência. São Paulo: Difel, 1983

. Topofilia - um estudo da percepção, atitudes e valores do meio ambiente. Londrina: Eduel, 2012.

TUCCI, Carlos Eduardo Morelli. Inundações e Drenagem Urbana. In: TUCCI, Carlos Eduardo Morelli; BERTONI, Juan Carlos. Inundações Urbanas na América do Sul. Associação Brasileira de Recursos Hídricos, Porto Alegre, $1^{\mathrm{a}}$ ed., 2003.

WORLD BANK INSTITUTIONS. The World Bank Annual Report 2010. United Nations, 2010.

ZANELLA, Maria Elisa. Inundações urbanas em Curitiba/PR: impactos, riscos e vulnerabilidade socioambiental no bairro Cajuru. Tese (Doutorado), Universidade Federal do Paraná - UFPR, Curitiba, PR, 2006. 